But, we ask, with the extension of mathematical knowledge will it not finally become impossible for the single investigator to embrace all departments of this knowledge? In answer let me point out how thoroughly it is ingrained in mathematical science that every real advance goes hand in hand with the invention of sharper tools and simpler methods which at the same time assist in understanding earlier theories and cast aside older more complicated developments. It is therefore possible for the individual investigator, when he makes these sharper tools and simpler methods his own, to find his way more easily in the various branches of mathematics than is possible in any other science.

The organic unity of mathematics is inherent in the nature of this science, for mathematics is the foundation of all exact knowledge of natural phenomena. That it may completely fulfil this high mission, may the new century bring it gifted masters and many zealous and enthusiastic disciples.

\title{
REPLY TO MR. J. L. COOLIDGE'S REVIEW OF HILL'S EUCLID.
}

I DEsIRE to thank the editors of the BuLLeTIN for their courtesy in acceding to my request that they should insert a reply to the review of my edition of the fifth and sixth books of Euclid's Elements by Mr. Coolidge, published in the February number of the Bulletin, as it contains statements which give an erroneous impression of the contents of the book.

The book differs from previous editions in two important particulars. These are :

1. The explanations of the fundamental definitions of the fifth book of Euclid.

2. The removal of the indirectness from Euclid's line of argument.

The second of these matters, though emphasized by italics on page viii of the preface, has been passed over without notice by the reviewer. The discovery of this indirectness and the possibility of removing it, were published by me in the Cambridge Philosophical Transactions, volume 16, part 4; and the importance of the work was recognized in the review of that paper in the Jahrbuch über die Fortschritte der Mathematik, volume 28 (1897), page 152. 
The first of the above-mentioned particulars is partially noticed by the reviewer in his account of the relative multiple scale. But he has penetrated so little into the spirit of the book that he describes relative multiple scales as being "equal" when certain conditions are satisfied. As relative multiple scales are not magnitudes the term "equal" is inappropriate. Under the conditions referred to, the relative multiple scales should be described as "the same." The reviewer also says: "The order of succession of the various multiples of $A$ and $B$ is called their relative multiple scale." It is not the "order," but "the device for showing the order."

The objections which the reviewer appears to feel most strongly, relate to the chapter on ratio, although the object of this chapter is only to make it possible to use the words " ratio" and "proportion." It is difficult to understand why the reviewer should describe my translation of Euclid's definition of ratio as a "soul-satisfying definition," and state that " a clear and precise idea of what a ratio is" is derivable therefrom, when the definition is preceded in the text by the statement that "It is only an endeavor to express in English the idea contained in the definition of ratio as stated in Euclid's Greek," and that "no use will be made of the definition in the argument."

The next statement of the reviewer must be quoted in full. "If we accept the axiom that a number $\rho$ may always be found of such a sort that the relative multiple scale of $\rho$ and 1 is equal to that of the two comparable magnitudes $A$ and $B$, then $\rho$ may be taken as the measure of the ratio of any pair of magnitudes having the same scale as $A$ and $B . "$ This is a misconception. The above statement is not an axiom, but a particular case of the fundamental proposition in the theory of relative multiple scales, which is proved in the paper referred to above. Euclid's determination of the fourth proportional to three given straight lines is a particular case of the same fundamental proposition which suffices for those who do not desire to go beyond the sixth book of Euclid. The proof of the above mentioned fundamental proposition is too difficult for those for whom this book is meant, and it has therefore been omitted.

The reviewer's objections to the omission of a reference to the axiom that "the whole is greater than its part," and to the omission of the statement of an assumption in the proofs given of the commutative and associative laws in the multiplication of positive integers, are beside the point in regard to an elementary text-book like this. To call the 
attention of beginners to such matters generally results in preventing them from learning those parts of the subject which it is desirable that they should master at this stage.

There are two other criticisms on points of detail. The word " proportionally" is used on page 29 before the definition of proportion has been given. In this case a footnote, identical with that on each of the two following pages, was unfortunately omitted.

The second criticism relates to the accidental omission of the single but important word "concurrent" in the definition of four harmonic lines. This omission I greatly regret.

I have now dealt with the whole of the criticisms, and leave it to those who may be interested to determine whether they justify the charge that "In some of the details the book is almost incredibly careless."

There is one matter left which is of interest to teachers :

The reviewer says: "Parts of Euclid are undoubtedly too difficult for beginners, and the book before us attempts to remove the greatest of these difficulties, the theory of proportion. In American books we seek to reach this end by an appeal to the analogy of algebra, but herein we depart entirely from Euclid's pattern.' I have not been able to determine the exact significance of the words "an appeal to the analogy of algebra," but I believe that those who will take up the fifth book of Euclid and examine how readily the ideas of the irrational number as developed by Dedekind can be used in connection with its results, will find that in rigor it far surpasses the modern attempts to turn the difficulties which Euclid faced and overcame.

University College, LoNDoN, M. J. M. HiLl. May 31, 1902.

\section{NOTES.}

With the issue of the present number of the Bulletin, Professor E. O. LovetT and Dr. C. L. Bouton retire from the editorial board. The Committee of Publication takes this opportunity to express its sense of obligation to the retiring editors for their faithful and valuable services.

THe third (July) number of volume 3 of the Transactions of the American Mathematical Society contain the following papers: "On the group defined for any given field 